\title{
Modelling the Effects of a Health Shock on the Armenian Economy ${ }^{1}$
}

\author{
Ani Asoyan, Central Bank of Armenia \\ ani.asoyan@cba.am \\ Vahagn Davtyan, Central Bank of Armenia \\ vahagn.davtyan@cba.am \\ Haykaz Igityan, Central Bank of Armenia \\ haykaz.igityan@cba.am \\ Hasmik Kartashyan, Central Bank of Armenia \\ hasmik.kartashyan@cba.am \\ Hovhannes Manukyan, Central Bank of Armenia \\ hovhannes.manukyan@cba.am
}

This paper extends the closed economy DSGE model in order to evaluate the impact of the coronavirus on the economy. Our model makes it clear that people's decisions to reduce consumption and working hours due to the health crisis lead to an economic recession. As a result, the spread of the virus declines. Expansionary monetary policy decreases the size of GDP decline, but it is costly in terms of public health. This result shows that there is a trade-off between the output loss caused by the pandemic and the health consequences of the pandemic.

Keywords: DSGE, health, pandemic, COVID-19

JEL Codes: E12, E52, I10
Citation: Asoyan, A., Davtyan, V., Igityan, H., Kartashyan, H. and Manukyan, H. (2020). Modelling the Effects of a Health Shock on the Armenian Economy. Russian Journal of Money and Finance, 79(4), pp. 18-44.

doi: $10.31477 /$ rjmf.202004.18

\section{Introduction}

As COVID-19 has spread throughout the world, epidemiological models have been widely used to predict the course of the pandemic. While these models are very useful, they do have an important shortcoming: they do not take into account the interaction between the behaviour of economic agents operating in the economy and the shock of the pandemic.

Policy makers certainly appreciate this interaction. For example, in their Financial Times op-ed of 18 March 2020, Ben Bernanke and Janet Yellen write:

\footnotetext{
1 The views expressed in this paper are those of the authors and do not necessarily represent the views or policies of the Central Bank of Armenia. The authors are grateful to the two anonymous reviewers for their great comments and constructive suggestions which have improved the paper.
} 
'In the near term, public health objectives necessitate people staying home from shopping and work, especially if they are sick or at risk. So production and spending must inevitably decline for a time?.

The latest pandemic shock has stimulated a modification of the standard dynamic stochastic general equilibrium (DSGE) models by the incorporation of a health block into them or by the linking of epidemiological models, which enables an understanding of the repercussions of the pandemic shock on the whole economy. A health shock can be interpreted as a negative labour supply shock, because sick people are either less productive, or they do not work at all. On the other hand, an pandemic generates negative shifts in demand for consumption. Taking into account the aforementioned facts, the shock can be considered a mixture of supply and demand shocks (Eichenbaum et al., 2020a).

Eichenbaum et al. (2020b) extend the canonical epidemiological model to study the interaction between economic decisions and pandemic. Their model implies that people's decision to cut back on consumption and work reduces the severity of the pandemic, as measured by total deaths. Moreover, a containment policy, represented by a tax on consumption, deepens the economic crisis, but reduces the number of infections and deaths. Their results indicate the presence of a trade-off between GDP dynamics and the number of deaths.

Krueger et al. (2020) use Eichenbaum et al. (2020b) model by composing several heterogeneous sectors that are differentiated by infection probability. They assume that the consumption of goods can be shifted from the marketplace to the home. Likewise, remote work can replace office work. The high flexibility of consumption and labour supply among sectors decreases the spread of infection and mitigates the loss of consumption. By introducing additional social distancing and hygiene measures, they show that infection rates decline drastically and the infection curve is reversed. The main idea is that in a flexible economy with high substitution of consumption across sectors and smoothly functioning labour markets, health shocks are less costly, and the economy quickly adapts to changes.

Acemoglu et al. (2020) develop the multi-risk SIR (Susceptible, Infectious, Recovered) model (MR-SIR) with three age groups: 'young', 'middle-aged', and 'old'. Infection and fatality rates vary across these groups. The result is that, in contrast to a uniform lockdown which treats all groups equally, targeted policies applied to a particular group show better performance in terms of both economic and health outcomes. With optimally targeted policies, it is possible to decrease the fatality rate for a given loss of output and vice versa. Semi-targetted policies that involve the strict lockdown of elders and allow other groups to be economically active achieve a lower fatality rate compared to a uniform policy and reduce economic damage. Combined targetted policies that decrease interactions between groups also outperform a uniform policy and significantly reduce the fatality rate and mitigate economic damage. Furthermore, combining targetted policies with 
other tools, such as social distancing between groups, testing, and isolation, can improve the trade-off between economic activity and public health.

Barrios and Hochberg (2020) and Durante et al. (2020) provide evidence that regions with higher civic culture engaged in more voluntary social distancing. For example, Sweden imposed relatively light restrictions. People tend to adopt social distancing when there is a specific incentive to do so in terms of the risk to health and the financial health cost. Maloney and Taskin (2020) also attribute voluntary actions to either fear or a sense of social responsibility.

Adda (2016), using high frequency data from France, finds that, while policies reducing inter-personal contacts such as school closure or the closure of public transport networks reduce disease prevalence, they are not cost effective. These policies would become cost effective for flu epidemics in instances when the death rate is above average.

Torój (2013) attempts to apply a New Keynesian open economy model to simulate the economic consequences of an influenza epidemic in Poland and measure the output loss (indirect cost) related to disease. The simulated indirect cost in the New Keynesian model turns out to be lower than the estimates that could possibly be obtained using a human capital approach. The reason for this discrepancy is the demand-oriented construction of the New Keynesian framework.

There are also papers that try to understand the optimal policies during a pandemic, both monetary and fiscal. Fornaro and Wolf (2020) study how monetary and fiscal policies can respond to the current pandemic by preventing the economy from falling into stagnation traps following persistent negative shocks to productivity growth. Authors find that monetary policy is likely to be insufficient in mitigating the slump induced by the coronavirus shock. Instead, aggressive fiscal policy interventions to support investment - and more broadly future productivity capacity - can play a key role in sustaining employment and growth.

Bigio et al. (2020) study optimal policies in response to the COVID-19 crisis in a two-sector Keynesian model. They discuss the effectiveness of credit policy versus lump-sum transfers and show that it depends on the extent of borrowing limits. In one extreme, when credit is ample, transfers are ineffective. In the opposite case, when credit is restricted, a credit policy turns ineffective. Hence, in developed economies, with ample credit limits, transfer policies are more likely to be neutral, whereas in emerging economies, with low credit limit, credit subsidy might not have a bite.

The difference in this paper, and its significance, are as follows: first, we model the health stock of a household explicitly and assume that individuals get utility from it (the modelling approach that we use is quite similar to that of Yagihashi and $\mathrm{Du}, 2015)$. At the same time, aggregate productivity is divided into exogenous component and health status. Second, the shock decreases the health stock of the household rather than the level of employment (see Guerrieri et al., 2020). 
This paper models the healthcare sector in the propagation of the pandemic shock and attempts to determine the effects of the spread of COVID-19 on economic decisions. In this framework, the role of monetary policy is also important, as coherent policy during the outbreak of a pandemic is a significant issue of concern for policymakers. The model is calibrated to the Armenian economy. Nevertheless, its structure is general and can be applied to other countries as well.

In our paper, we extend the standard closed economy New Keynesian DSGE model by incorporating a health block into it. The health block is introduced into the model via its accumulation process, rather than being modelled explicitly via the SIR model, because the negative health shock in our framework and the increase in the number of infected people in the framework linked with the SIR model affect the economy in the same way and do not differ significantly from each other. There are three main agents: households, firms, and the central bank. The representative household consumes health and non-health goods, supplies labour in health and non-health sectors, and does investment for capital accumulation which is divided into health capital and physical capital accumulation. Firms are divided into two sectors: the health sector and an 'other' sector. They use effective capital and effective labour to produce consumption and investment goods. It should be noted that the effectiveness of labour is measured by the household's health status. The model highlights that expansionary monetary policy during the pandemic shock, in spite of the fact that it stimulates the economy in the short run, promotes the maintenance of a lower level of health stock in that period. In the baseline framework, government is passive and does not intervene at all, because the main objective of the paper is to study the behaviour of economic agents in response to pandemic shock.

The paper then discusses the optimal monetary policy during COVID-19. A committed Ramsey planner minimising the variation of inflation can achieve a very small decline in output and inflation but a huge decline in health status. When the planner also considers health, he or she can achieve a smaller decline in health status and output compared to the case under the Taylor rule. The cost of this is expressed in relatively high inflation. Later, we introduce a government which tries to lessen the negative production externalities from the declining health. The government section is modelled in a simple manner, and we assume that the deficit can be financed from external sources. By comparing the simple rule with the optimal, we find that a committed policy results in a better outcome both in terms of health and economic performance. We also allow government to finance health spending. This allows a gain in health status but creates inflation pressures. Government intervention results in an increase in budget deficit and debt.

The paper also discusses the robustness of the results of the model's different specifications. Firstly, we relax the assumption of the separability of consumption and health in the household's utility function. Secondly, the more general case of 
health investment, in the form of the constant elasticity of substitution (CES) function with health consumption and isolation, is used to avoid unit elasticity of substitution between them. Then we introduce isolation time to the utility function, removing isolation costs from budget constraints. The responses of the model variables to these three different specifications are in line with the results of the baseline model.

The rest of the paper is organised as follows. Section 2 develops the model. Section 3 illustrates the calibration of the parameters. Section 4 presents the main results of the model, representing the dynamics of the main economic variables in response to the health shock, then it discusses optimal monetary policy and introduces fiscal policy. Section 5 tests the robustness of the model's results with different specifications. Finally, Section 6 concludes.

\section{The model}

This section develops the standard set of micro-foundations in the DSGE model, allowing the taking of health and its economic implications into account. The basic structure of the model is as follows. Households receive utility from the consumption of non-health goods, from leisure, and from being healthy. Health status is introduced to the household utility function à la Yagihashi and Du (2015), and it indicates the accumulation of health stock. Differently from their approach, this paper models health investment as a function of medical goods and isolation. Isolation time is produced in the health sector (as e.g. time taken for hospital treatment). The representative household works in the health and non-health sectors, consumes goods which are divided into health and non-health goods, and makes investments in the accumulation of health and non-health capital. Households solve two optimisation problems. Firstly, they minimise their total expenditures and decide how many health and non-health goods to consume. Secondly, they maximise their utility function subject to the budget constraints that balance all sources of income with all uses of income within each period. Households are assumed to own all factors of production in the economy (capital and labour in our model). They also have access to the government bonds that pay a nominal riskless interest rate. Households also choose the utilisation rate of capital and supply it to domestic firms which produce intermediate goods. Firms in the non-health production sector use labour and capital resources to produce non-health consumption goods. Health sector producers use the same resources to produce health consumption goods and isolation. The intermediate goods producers in each sector use the Cobb-Douglas production function. The monetary authority sets the nominal interest rate via the Taylor rule. The schematic representation of the model is captured in Figure 1. 
Figure 1. Model environment

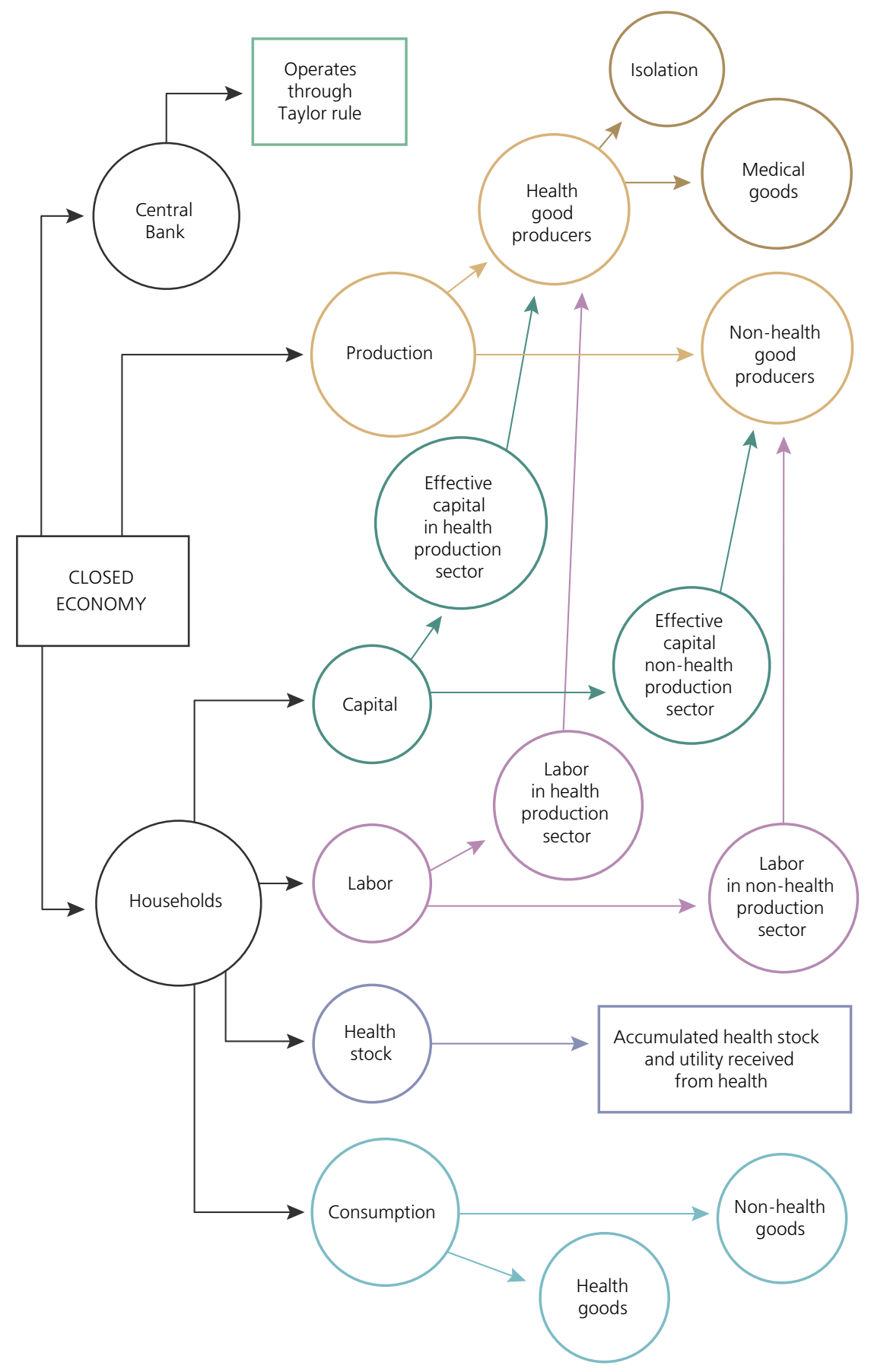




\subsection{Households}

A household seeks to maximise the following utility function

$$
E_{t} \sum_{j=0}^{\infty} \beta^{j}\left(\frac{C_{N, t+j}^{1-\sigma}}{1-\sigma}-\chi_{N} \frac{N_{N, t+j}^{1+\varphi_{N}}}{1+\varphi_{N}}-\chi_{H} \frac{N_{H, t+j}^{1+\varphi_{H}}}{1+\varphi_{H}}+\psi \frac{H_{t+j}^{1-\eta}}{1-\eta}\right) \rightarrow \max ,
$$

where $E_{t}$ is the expectation operator conditional on information available at time $t, \beta$ is the discount factor, $C_{N, t}$ is the consumption of non-health goods, $N_{N, t}$ and $N_{H, t}$ are working hours in the non-health and health sectors, respectively, $\varphi_{N}$ and $\varphi_{H}$ are the inverses of the Frisch elasticity of labour supply, $\chi_{N}$ and $\chi_{H}$ are the disutilities from working in the non-health and health sectors, respectively, $H_{t}$ is the household's health status, $\sigma$ and $\eta$ are, respectively, the inverses of the intertemporal elasticities of substitution for non-health goods consumption and health status, and $\psi$ is the utility weight on health status.

A household tries to maximise the utility function subject to the following budget constraint for each $t$ :

$$
\begin{aligned}
& C_{N, t}+I_{N, t}+I_{H, t}+\frac{B_{t}}{P_{N, t}}+a\left(u_{H, t}\right) K_{H, t}+a\left(u_{N, t}\right) K_{N, t}+\frac{P_{H, t}}{P_{N, t}} \frac{W_{N, t}}{P_{H, t}} N_{M, t} \\
& +\frac{P_{H, t}}{P_{N, t}} C_{H, t} \leq \frac{W_{N, t}}{P_{N, t}} N_{N, t}+\frac{W_{H, t}}{P_{N, t}} N_{H, t}+\frac{R_{t-1} B_{t-1}}{P_{N, t}}+\frac{K_{N, t}^{e f f} R_{N, t}^{K}}{P_{N, t}}+\frac{K_{H, t}^{e f f} R_{H, t}^{K}}{P_{N, t}}+\frac{D i v_{t}}{P_{t}},
\end{aligned}
$$

where $I_{N, t}$ is the investment of capital in the non-health production sector, $I_{H, t}$ is the investment of capital in the health production sector, $W_{N, t}$ and $W_{H, t}$ are, respectively, the nominal wage rates in the non-health and health sectors, $P_{N, t}$ and $P_{H, t}$ are price indices for non-health and health consumption goods, respectively, $B_{t}$ is the amount of government bonds that pay a nominal gross interest rate of $R_{t}$,

$\frac{W_{N, t}}{P_{H, t}} N_{M, t}$ is the isolation (hours) represented in terms of health consumption goods, $R_{i, t}^{k}$ is the rental price of effective capital $K_{i, t}^{e f f}, u_{i, t}$ is the capital utilisation rate, $a\left(u_{i, t}\right)$ is the cost of setting the utilisation rate $(i=N, H)$ and $\operatorname{Div}_{t}$ are the dividends of firms which are owned by the household.

We model the health status of the household as a stock which depreciates over time. Therefore, households make investments consisting of medical goods and isolation time for the maintenance of their health status. It should be emphasised that isolation hours are costly for households, as they could spend their time on work in the non-health sector. Consequently, the opportunity cost of isolation is the real wage in the non-health sector (see Figure 2).

The occurrence of a health disaster is captured in the following health accumulation equation: ${ }^{2}$

\footnotetext{
${ }^{2}$ We could have isolation without wage in health investment and still obtain our main results. Simulations are available upon request.
} 


$$
H_{t+1}=\left(1-\delta_{h}\right) H_{t}+C_{H, t}^{\alpha_{h}}\left(\frac{W_{N, t}}{P_{H, t}} N_{M, t}\right)^{1-\alpha_{h}}-\varepsilon_{t}^{C O V I D-19},
$$

where $\delta_{h}$ is the depreciation rate of health. The middle term is health investment conducted by health spending $\left(C_{H, t}\right)$ and isolation $\left(\frac{w_{N, t}}{P_{H, t}} N_{M, t}\right)$. The schematic representation of the accumulation of health stock is represented in Figure 3.

Figure 2. The opportunity cost of isolation

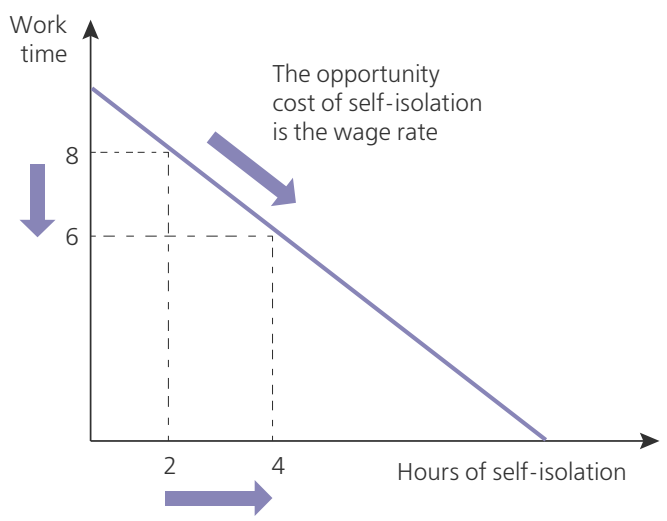

Figure 3. Accumulation of health stock

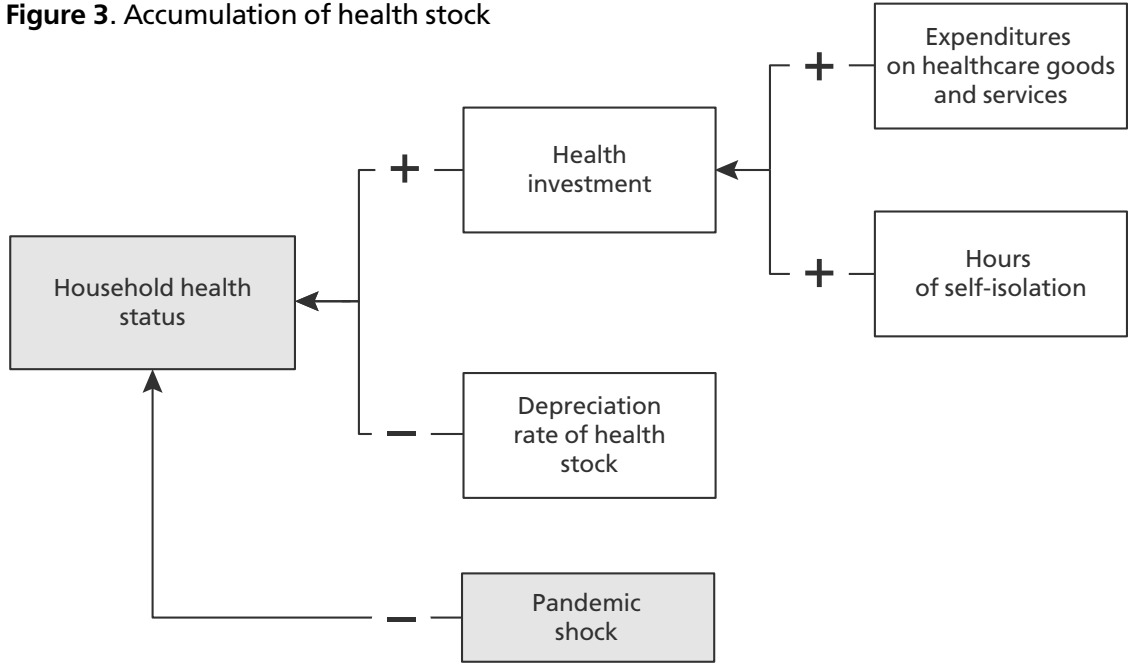

Capital stock evolves according to the following equation:

$$
K_{i, t+1}=\left(1-\delta_{i}\right) K_{i, t}+I_{i, t} \quad i=N, H,
$$

where $\delta_{i}$ is the depreciation rate of capital. Effective capital is a positive function of physical capital $K_{t}$, utilisation $u_{t}$, and labour $N_{t}$ : 


$$
K_{i, t}^{e f f}=\gamma_{m}^{i} K_{i, t} u_{i, t} N_{i, t}^{\gamma_{n}^{i}} \quad i=N, H
$$

Equation (2.1.5) shows that if labour supply decreases, it also leads to a decrease in effective capital. This method of modelling effective capital provides a decline in capital during COVID shock.

Following Christiano et al. (2011), we use the functional form of capital utilisation given by:

$$
a\left(u_{i, t}\right)=\frac{1}{2} \xi_{a}^{i} \xi_{b}^{i} u_{i, t}^{2}+\xi_{b}^{i}\left(1-\xi_{a}^{i}\right) u_{i, t}+\xi_{b}^{i}\left(\frac{\xi_{a}^{i}}{2}-1\right) \quad i=N, H,
$$

where $\xi_{a}$ and $\xi_{b}$ are parameters of the function. This function is very convenient for the analysis because it becomes zero in a steady state.

Inserting (2.1.4), (2.1.5), and (2.1.6) into (2.1.2) and maximising (2.1.1) subject to (2.1.2) and (2.1.3), we get the following set of first order conditions:

$$
\begin{aligned}
& C_{N, t}: C_{N, t}^{-\sigma}-\lambda_{t}=0 \text {, } \\
& C_{H, t}: \quad-\lambda_{t} \frac{P_{H, t}}{P_{N, t}}+\mu_{t} \alpha_{h}\left(\frac{W_{N, t} N_{M, t}}{P_{H, t} C_{H, t}}\right)^{1-\alpha_{h}}=0, \\
& N_{N, t}: \quad-\chi_{N} N_{N, t}^{\varphi_{N}}+\lambda_{t} \frac{W_{N, t}}{P_{N, t}}+\lambda_{t} u_{N, t} \gamma_{m}^{N} \gamma_{n}^{N} N_{N, t}^{\gamma_{n}^{N}-1} \frac{K_{N, t} R_{N, t}^{k}}{P_{N, t}}=0 \\
& N_{H, t}: \quad-\chi_{H} N_{H, t}^{\varphi_{H}}+\lambda_{t} \frac{W_{H, t}}{P_{N, t}}+\lambda_{t} u_{H, t} \gamma_{m}^{H} \gamma_{n}^{H} N_{H, t}^{\gamma_{n}^{H}-1} \frac{K_{H, t} R_{H, t}^{k}}{P_{N, t}}=0, \\
& N_{M, t}: \quad-\lambda_{t} \frac{P_{H, t}}{P_{N, t}} \frac{W_{N, t}}{P_{H, t}}+\mu_{t}\left(1-\alpha_{h}\right)\left(\frac{W_{N, t}}{P_{H, t}}\right)^{1-\alpha_{h}}\left(\frac{C_{H, t}}{N_{M, t}}\right)^{\alpha_{h}}=0, \\
& B_{t}: \quad-\frac{\lambda_{t}}{P_{N, t}}+\beta E_{t} \lambda_{t+1} \frac{R_{t}}{P_{N, t+1}}=0, \\
& K_{N, t+1}: \quad-\lambda_{t}+\beta E_{t} \lambda_{t+1} \\
& \times\left(\left(u_{N, t+1} \gamma_{m}^{N} N_{N, t+1}^{\gamma_{n}^{N}}\right) \frac{R_{N, t+1}^{K}}{P_{N, t+1}}+\left(1-\delta_{N}-a\left(u_{N, t+1}\right)\right)\right)=0, \\
& K_{H, t+1}:-\lambda_{t}+\beta E_{t} \lambda_{t+1} \\
& \times\left(\left(u_{H, t+1} \gamma_{m}^{H} N_{H, t+1}^{\gamma_{n}^{H}}\right) \frac{R_{H, t+1}^{K}}{P_{N, t+1}}+\left(1-\delta_{H}-a\left(u_{H, t+1}\right)\right)\right)=0, \\
& H_{t+1}: \quad-\mu_{t}+\beta E_{t} \psi H_{t+1}^{-\eta}+\beta E_{t} \mu_{t+1}\left(1-\delta_{h}\right)=0,
\end{aligned}
$$




$$
\begin{aligned}
& u_{N, t}: \quad \gamma_{m}^{N} N_{N, t}^{\gamma_{n}^{N}} \frac{K_{N, t} R_{N, t}^{K}}{P_{N, t}}-a\left(u_{N, t}^{\prime}\right) K_{N, t}=0, \\
& u_{H, t}: \quad \gamma_{m}^{H} N_{H, t}^{\gamma_{n}^{H}} \frac{K_{H, t} R_{H, t}^{K}}{P_{N, t}}-a\left(u_{H, t}^{\prime}\right) K_{H, t}=0,
\end{aligned}
$$

where $\lambda_{t}$ ang $\mu_{t}$ are Lagrange multipliers.

Combining (2.1.7) and (2.1.12), we get the intertemporal consumption equation (Euler equation):

$$
C_{N, t}^{\sigma}=\frac{1}{\beta} E_{t} C_{N, t+1}^{\sigma} \Pi_{N, t+1} R_{t}^{-1} .
$$

Rewriting (2.1.9) and (2.1.10), then using the definition of a Lagrangian multiplier (2.1.7), we are left with the labour supply equations for a household:

$$
\begin{aligned}
& \chi_{N} N_{N, t}^{\varphi_{N}} C_{N, t}^{\sigma}=\frac{W_{N, t}}{P_{N, t}}+u_{N, t} \gamma_{m}^{N} \gamma_{n}^{N} N_{N, t}^{\gamma_{n}^{N}-1} \frac{K_{N, t} R_{N, t}^{k}}{P_{N, t}}, \\
& \chi_{H} N_{H, t}^{\varphi_{H}} C_{N, t}^{\sigma}=\frac{W_{H, t}}{P_{N, t}}+u_{H, t} \gamma_{m}^{H} \gamma_{n}^{H} N_{H, t}^{\gamma_{n}^{H}-1} \frac{K_{H, t} R_{H, t}^{k}}{P_{N, t}} .
\end{aligned}
$$

Substituting $\lambda_{t}$ from (2.1.7) in equations (2.1.13) and (2.1.14), the capital supply equations take the forms:

$$
\begin{aligned}
& \beta E_{t}\left(\frac{C_{N, t}}{C_{N, t+1}}\right)^{\sigma}\left(\left(u_{N, t+1} \gamma_{m}^{N} N_{N, t+1}^{\gamma_{n}^{N}}\right) \frac{R_{N, t+1}^{K}}{P_{N, t+1}}+\left(1-\delta_{N}-a\left(u_{N, t+1}\right)\right)\right)=1, \\
& \beta E_{t}\left(\frac{C_{N, t}}{C_{N, t+1}}\right)^{\sigma}\left(\left(u_{H, t+1} \gamma_{m}^{H} N_{H, t+1}^{\gamma_{n}^{H}}\right) \frac{R_{H, t+1}^{K}}{P_{N, t+1}}+\left(1-\delta_{H}-a\left(u_{H, t+1}\right)\right)\right)=1 .
\end{aligned}
$$

Combining (2.1.8) and (2.1.11), we get that the consumption of health goods is proportional to isolation hours:

From (2.1.15):

$$
\frac{W_{N, t}}{P_{H, t}} N_{M, t}=\frac{1-\alpha_{h}}{\alpha_{h}} C_{H, t} .
$$

$$
\beta E_{t}\left(\psi H_{t+1}^{-\eta}+\left(\frac{C_{H, t+1}}{\frac{W_{N, t+1}}{P_{H, t+1}} N_{M, t+1}}\right)^{1-\alpha_{h}} \frac{1}{\alpha_{h}} \frac{P_{H, t+1}}{P_{N, t+1}} \frac{1-\delta_{h}}{C_{N, t+1}^{\sigma}}\right)=\left(\frac{C_{H, t}}{\frac{W_{N, t}}{P_{H, t}} N_{M, t}}\right)^{1-\alpha_{h}} \frac{1}{\alpha_{h}} \frac{P_{H, t}}{P_{N, t}} \frac{1}{C_{N, t}^{\sigma}},
$$

which determines the optimality condition for health investment.

Rewriting (2.1.16) and (2.1.17), we are left with optimality conditions for the capital utilisation rate: 


$$
\begin{gathered}
\xi_{m} \xi_{n} u_{N, t}+\xi_{n}\left(1-\xi_{m}\right)=\gamma_{m}^{N} N_{N, t}^{\gamma_{n}^{N}} \frac{R_{N, t}^{K}}{P_{N, t}}, \\
\xi_{a} \xi_{b} u_{H, t}+\xi_{b}\left(1-\xi_{a}\right)=\gamma_{m}^{H} N_{H, t}^{\gamma_{n}^{H}} \frac{R_{H, t}^{K}}{P_{N, t}}
\end{gathered}
$$

\subsection{Firms}

On the production side, there are two sectors: the health sector and the nonhealth sector.

\subsubsection{Health goods production}

Intermediate health goods producers operate in a monopolistic competitive environment and use the Cobb-Douglas production function given as follows:

$$
Y_{H, t}=A_{H, t}\left(K_{H, t}^{e f f}\right)^{\alpha_{H}}\left(N_{H, t} H_{t}\right)^{1-\alpha_{H}} \text {, }
$$

where $A_{H, t}$ is the cyclical technological process and $\alpha_{H}$ is the share of effective capital in the production function.

Intermediate health goods producers seek to maximise their profits, which results in an optimal allocation of effective capital and labour:

$$
\frac{r_{H, t}^{k}}{w_{H, t}^{r}}=\frac{\alpha_{H}}{1-\alpha_{H}} \frac{N_{H, t}}{K_{H, t}^{e f f}} .
$$

The real marginal cost of the health sector is a function of the real wage and the real rent of effective capital, along with health stock and temporary productivity:

$$
M C_{H, t}=\left(\frac{r_{H, t}^{k}}{\alpha_{H}}\right)^{\alpha_{H}}\left(\frac{w_{H, t}^{r}}{1-\alpha_{H}}\right)^{1-\alpha_{H}} \frac{1}{A_{H, t} H_{t}^{1-\alpha_{H}}} \frac{P_{N, t}}{P_{H, t}}
$$

Firms set prices following Calvo (1983): in a given period only a $(1-\theta)$ fraction of intermediate firms can re-optimise their prices. Solving the price setting problem, we derive a nonlinear Phillips curve as in Sims and Wu (2019):

$$
\begin{gathered}
x_{1, t}^{H}=\frac{Y_{H, t} M C_{H, t}}{C_{N, t}^{\sigma}}+\theta_{H} \beta E_{t} \Pi_{H, t+1}^{\varepsilon_{H}} x_{1, t+1}^{H}, \\
x_{2, t}^{H}=\frac{Y_{H, t}}{C_{N, t}^{\sigma}}+\theta_{H} \beta E_{t} \Pi_{H, t+1}^{\varepsilon_{H}-1} x_{2, t+1}^{H}, \\
\Pi_{H, t}^{*}=\frac{\varepsilon_{H}}{\varepsilon_{H}-1} \Pi_{H, t} \frac{x_{1, t}^{H}}{x_{2, t}^{H}},
\end{gathered}
$$




$$
\Pi_{H, t}^{1-\varepsilon_{H}}=\theta_{H}+\left(1-\theta_{H}\right)\left(\Pi_{H, t}^{*}\right)^{1-\varepsilon_{H}}
$$

where $x_{1, t}^{H}$ and $x_{2, t}^{H}$ are auxiliary variables.

\subsubsection{Non-health goods production}

The problem for intermediaries in the non-health sector is identical to this in the health care sector.

The production function of intermediate non-health goods is represented by the following Cobb-Douglas function:

$$
Y_{N, t}=A_{N, t}\left(K_{N, t}^{e f f}\right)^{\alpha_{N}}\left(N_{N, t} H_{t}\right)^{1-\alpha_{N}} .
$$

The equations for optimal allocation of resources and real marginal cost are as follows:

$$
\begin{gathered}
\frac{r_{N, t}^{k}}{w_{N, t}^{r}}=\frac{\alpha_{N}}{1-\alpha_{N}} \frac{N_{N, t}}{K_{N, t}^{e f f}} \\
M C_{N, t}=\left(\frac{r_{N, t}^{k}}{\alpha_{N}}\right)^{\alpha_{N}}\left(\frac{w_{N, t}^{r}}{1-\alpha_{N}}\right)^{1-\alpha_{N}} \frac{1}{A_{N, t} H_{t}^{1-\alpha}} .
\end{gathered}
$$

The Phillips curve of non-health sector goods is given by the following set of equations:

$$
\begin{gathered}
x_{1, t}^{N}=\frac{Y_{N, t} M C_{N, t}}{C_{N, t}^{\sigma}}+\theta_{N} \beta E_{t} \Pi_{N, t+1}^{\varepsilon_{N}} x_{1, t+1}^{N}, \\
x_{2, t}^{N}=\frac{Y_{N, t}}{C_{N, t}^{\sigma}}+\theta_{N} \beta E_{t} \Pi_{N, t+1}^{\varepsilon_{N}-1} x_{2, t+1}^{N}, \\
\Pi_{N, t}^{*}=\frac{\varepsilon_{N}}{\varepsilon_{N}-1} \Pi_{N, t} \frac{x_{1, t}^{N}}{x_{2, t}^{N}} \\
\Pi_{N, t}^{1-\varepsilon_{N}}=\theta_{N}+\left(1-\theta_{N}\right)\left(\Pi_{N, t}^{*}\right)^{1-\varepsilon_{N}} .
\end{gathered}
$$

\subsection{Market clearing conditions}

The output of the health sector is divided into the consumption of health goods and isolation represented in terms of consumption goods:

$$
Y_{H, t}=C_{H, t}+\frac{W_{N, t}}{P_{H, t}} N_{M, t}
$$

On the other hand, the production of non-health goods is the sum of nonhealth consumption, investment in the health and non-health sectors, and the capital utilisation costs of both sectors.

$$
Y_{N, t}=C_{N, t}+I_{N, t}+I_{H, t}+a\left(u_{N, t}\right) K_{N, t}+a\left(u_{H, t}\right) K_{H, t}
$$




\subsection{Monetary policy}

To close the model, the endogenous interest rate must be set by the monetary authority. We assume that the central bank implements an inflation targeting policy via a Taylor-type interest rate rule:

$$
\frac{R_{t}}{R^{s S}}=\left(\frac{R_{t-1}}{R^{s S}}\right)^{\rho_{r}}\left\{\left(\frac{E_{t} \Pi_{N, t+1}}{\Pi_{N}^{s S}}\right)^{\mu_{\pi}}\left(\frac{Y_{N, t}+Y_{H, t}}{Y_{N}^{s S}+Y_{H}^{s S}}\right)^{\mu_{y}}\right\}^{\left(1-\rho_{r}\right)} .
$$

The central bank's rule has some persistence and reacts to inflation expectations on non-health goods and the deviation of output from its steady state.

\section{Calibration}

This section presents our baseline calibration. The model is calibrated on a quarterly basis. First, we discuss the parameters, which differ within sectors. Particularly, we set the parameter of the price stickiness of non-health goods to 0.8 , i.e. prices stay unchanged for five quarters on average. By contrast, we calibrate the parameter of the price stickiness of health goods at $\theta_{H}=0.5$ (prices stay unchanged for two quarters on average); here, we make assumption that during a health shock the price of health related goods is more flexible as compared to normal times, when the relative price stickiness of health and non-health goods is very close or the situation is even reversed.

The parameter of the labour supply elasticity of the non-health sector, $\varphi_{N}$, is set to 1.2 and the same parameter for the health production sector is set to 2.5 , indicating that, all other things being equal, people are less willing to work in the health sector due to the higher risk of getting infected (the common value of this parameter is 2 (see Christiano et al., 2011). As for the parameters for the disutility of working, we set $\chi_{N}=2$ and $\chi_{H}=8$ (the non-health and health sectors, respectively), indicating the fact that in equilibrium the steady-state level of employment in the non-health sector is higher. We have an effective capital equation for each sector, and there two parameters (one for each sector), $\gamma_{n}^{N}=4$ and $\gamma_{n}^{H}=1.1$. The latter four parameters are calibrated in such a way that, in a steady state (see Appendix A), health sector employment is about 5\% (to match the Armenian data) and, consequently, the rest are employed in the non-health sector.

The rest of the parameters presented we set equal to each other in the two sectors, so as not to impose further heterogeneity among the sectors, namely $\alpha$, the share of capital in the production function, is set to 0.5 for both sectors, consistent with the stylised facts for the Armenian economy. The depreciation rates of capital employed in both sectors, $\delta_{H}$ and $\delta_{N}$, are calibrated to the common value of 0.025 used in DSGE literature (Smets and Wouters, 2007; FernándezVillaverde, 2010).

Now we turn to the parameters directly related to health stock, namely, the depreciation rate of health stock $\left(\delta_{h}\right)$, the share of health goods in health 
investment $\left(\alpha_{h}\right)$, the utility weight on health status $(\psi)$, and the intertemporal elasticity of substitution for health status $(\eta)$. They are set at $0.025,0.25,1.1$, and 3 , respectively. These parameters are not common, because the health sector is not modelled explicitly in the DSGE framework, at least not prior to the COVID-19 pandemic. Thus, these parameters are calibrated based on our knowledge of their nature (for example, we assume that, on average, people consume fewer medical goods for maintaining their health level compared to leading a healthy lifestyle), and to match the data reported worldwide regarding the effects of the pandemic. As an extension, we also do model sensitivity analysis with respect to these parameters to see to what extent they affect the impulse response functions of health shock.

For the rest of the parameters presented in the model we set following values. The coefficient of the inverse of the intertemporal elasticity of substitution for nonhealth goods consumption $(\sigma)$ is 1.1 , the discount factor $\beta$ is 0.99 , implying an annual real interest rate of $4 \%$. Following a wide range of literature (Galí and Monacelli, 2005; Christiano et al., 2011; etc.), we set $\varepsilon_{H}$ and $\varepsilon_{N}$ (the elasticity of substitution among intermediate goods for the health and non-health sectors) at 6 , implying a $20 \%$ mark-up in a steady state.

The coefficients of the reaction of the interest rate to inflation expectations $\mu_{\pi}$ and the output gap $\mu_{y}$ are set at 1.2 and 0.2 , respectively. The value of the smoothing parameter in the Taylor-type rule $\rho_{r}$ is calibrated to 0.6 . This calibration is very close to the values used in the literature.

\section{Results}

This section discusses the dynamics of the main variables of the model in response to health shock and the response of monetary policy to health shock, and it includes some sensitivity analysis as well. All the graphs of impulse responses represent time in quarters (horizontal axis), and the vertical axes show the percentage deviation of the variables from steady states. ${ }^{3}$

\subsection{Impulse responses to health shock}

Figure 4 displays the impulse response functions to a negative health shock, which indicates the extent of the outbreak of the COVID-19 pandemic in the economy. Health shock is calibrated in such a way as to match the $16.2 \%$ quarteron-quarter decline in Armenian GDP growth in 2020Q2.

Negative health shock decreases the health status of households. The harder the shock hits, the more isolated people become in order to recover their health status. During a pandemic, households increase their demand for medical goods and decrease their consumption of non-health goods. To meet the additional

3 The simulations are implemented within the Dynare software platform. 
Figure 4. Impulse responses to health shock
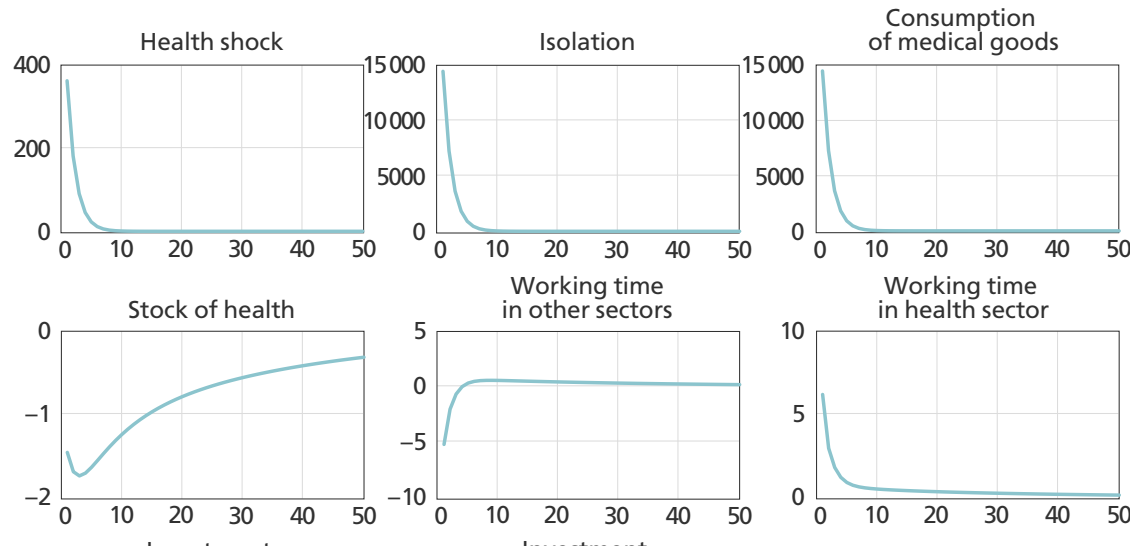

Working time

Working time
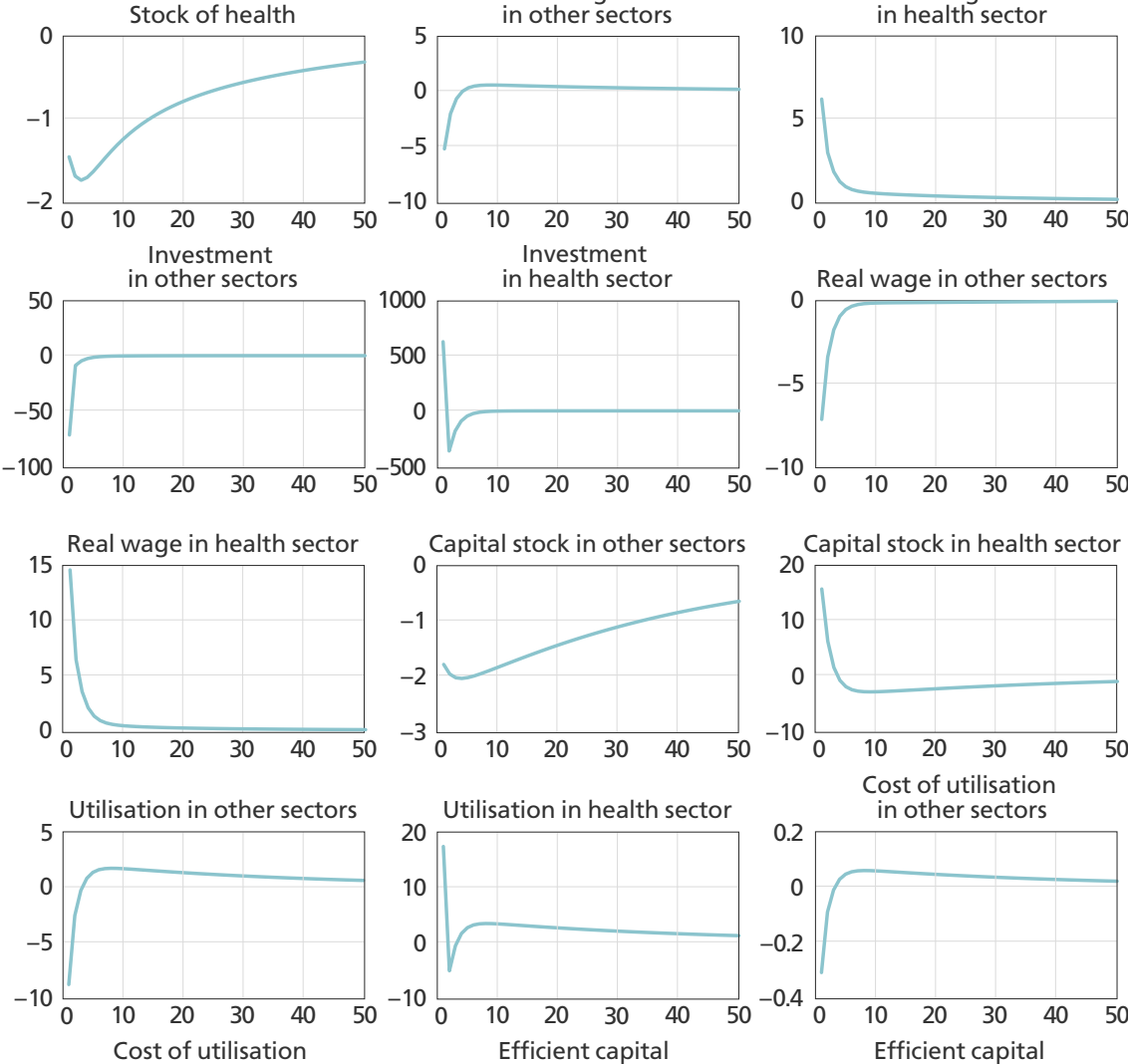

Cost of utilisation

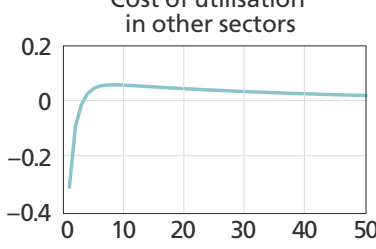

in health sector
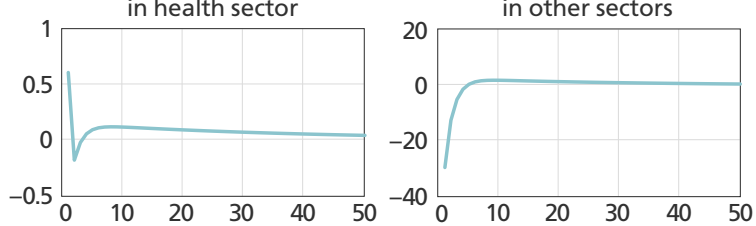

Efficient capital
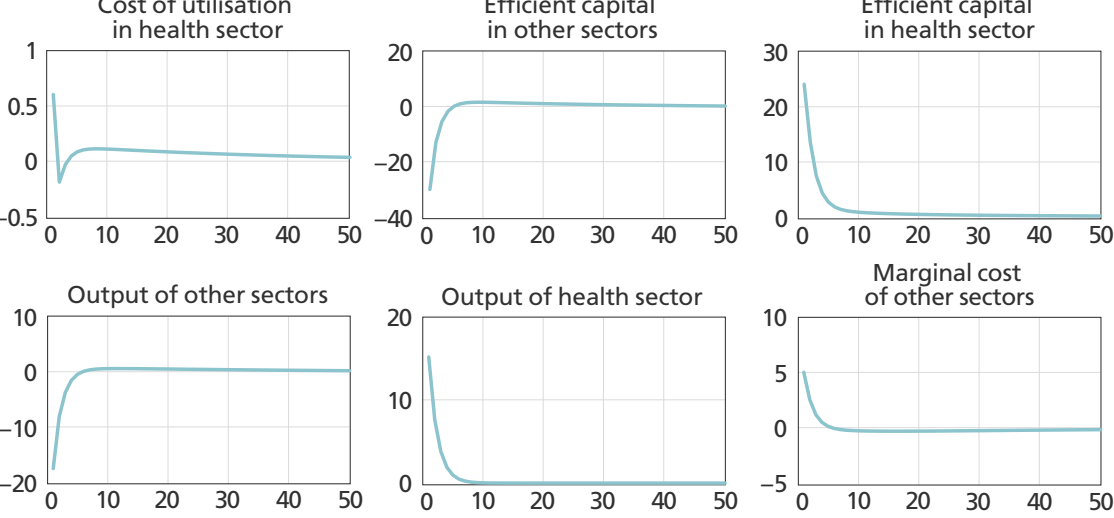
Figure 4. Continuation
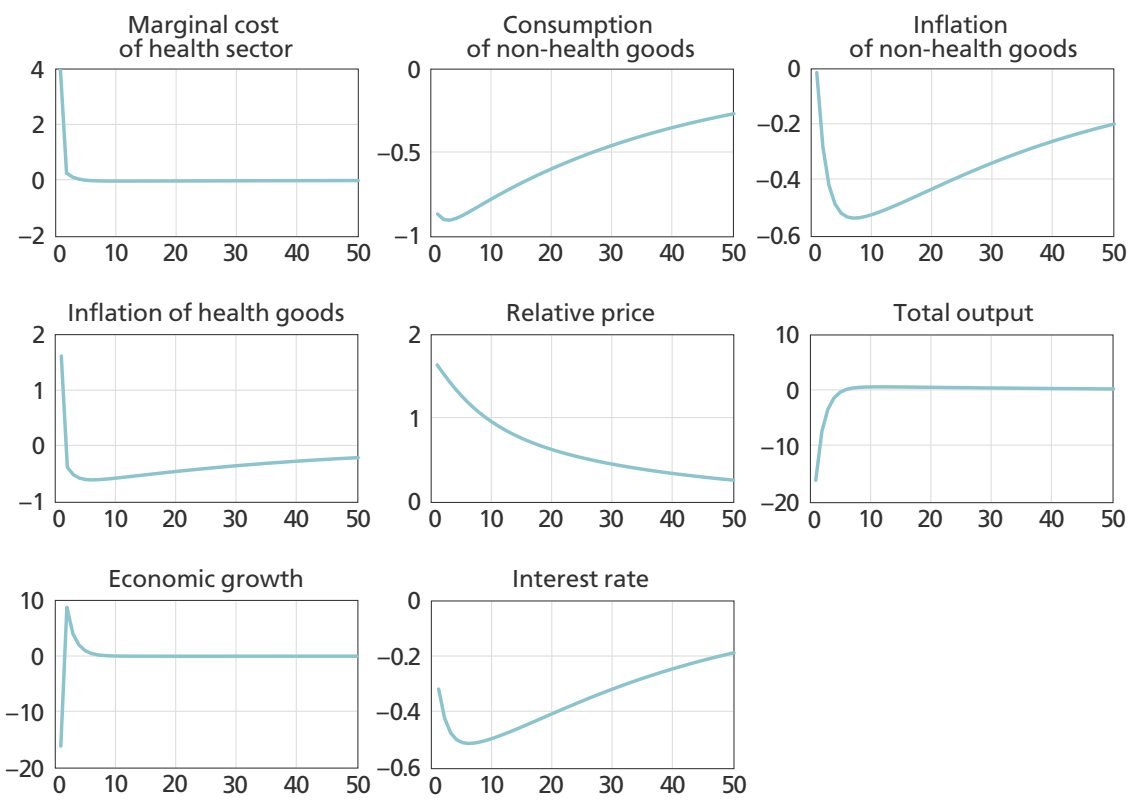

demand, firms in the health sector hire more labour. On the other hand, output in other sectors decreases. Wages respond similarly. The real wage increases in the health sector, due to the high demand for labour, and decreases in other sectors. As a result, labour increases in the health sector and decreases in the non-health sector. The increase in the consumption of medical goods and isolation time leads health stock to recover and converge to its steady state at the end of the simulation period. Higher wages in the health sector bring marginal costs up, which accelerates inflation.

The decrease in real wages in the non-health goods sector shrinks marginal costs. Additionally, the effect of the decrease in health stock exceeds the effect of wages, which results in an increase in marginal costs.

The reason for the higher growth of the non-health sector's marginal costs is that in the health goods sector, marginal costs also negatively depend on the relative price of health to non-health goods.

The relative price of health to non-health goods increases, and health goods become relatively expensive.

This dynamic restricts the increase of marginal cost in the health goods sector. In the health sector, prices are more flexible, and price elasticity with respect to marginal costs is higher. This accelerates inflation. On the other hand, the presence of higher price stickiness in the non-health goods sector staves off inflation. Higher demand in the health goods sector also requires more investment to boost production. This leads to an increase in investment in the health sector 
and a decline in investment in the other sector. As a result, more capital is accumulated and utilised as a component of effective capital. The use of capital shifts from other sectors to the health sector. That is why both capital and its utilisation increase in the health sector and decline in other sectors. Therefore, by increasing capital utilisation, its cost also increases in the health sector and decreases in other sectors. As a growing function of capital stock and the utilisation of capital, effective capital increases in the health sector and declines in other sectors as well. Effective capital and labour are considered inputs to production. Thus, an increase in production factors in the health sector entails an increase in production itself. The output in other sectors declines. The share of the health sector in total GDP is small, which results in a decline of total production due to the large decrease in the non-health sector. Despite the huge decline in total output, deflation is not so high, indicating the supply and demand nature of the health shock. The monetary authority reacts to deflation and negative output by decreasing the interest rate modestly.

\subsection{Sensitivity analysis}

In this section, we provide a sensitivity analysis to assess the results of health shock by changing the values of some structural parameters of the model. We check to what extent the impulse response functions of health shock depend on some health-related parameters, because there is no evidence for these parameters in the literature. Figure 10 (Appendix D) shows the impulse response functions of health shock for two alternative calibrations of the depreciation rate of health stock, together with the baseline calibration.

First, we set $\delta_{h}=0.01$, so health status (stock) depreciates at a slower pace. Compared to the baseline calibration, health stock declines less during the first six quarters and, because of high persistence, it converges to the steady state later. Then we set it to 0.075 , to see the adverse situation. In this case, health stock declines more during the same quarters but converges to the steady state faster because of low persistence.

The next exercise tests the sensitivity of the model with respect to the parameter for health's share in a household's utility (see Figure 11 in Appendix D). Applying the same logic as for the depreciation rate, we first set it equal to 0.4, and then to 8 . In the case of $\psi=8$, households value their health status much more compared to the baseline case, which results in less decline of health stock and output. A higher inverse of the intertemporal elasticity of substitution for health status $\eta$ means that households smooth their health more throughout time, leading to the lower decline of the latter compared to the baseline (see Figure 12 in Appendix D). The results show that, though the size of response for some variables changes, the direction and dynamics of this responses remain almost the same. 


\subsection{Expansionary monetary policy during the COVID-19 shock}

This section studies the behaviour of the economy when the central bank pursues expansionary monetary policy during the health shock. ${ }^{4}$ Results are captured in Figure 5.

The subsequent unanticipated temporary decrease in the nominal interest rate (deviation from the Taylor rule) raises demand for non-health goods. This forces firms to increase labour demand in other sectors and pushes up real wages. Higher wages motivate households to supply more working time in other sectors and decrease isolation time. As a result, expansionary monetary policy mitigates the reduction in total output and economic growth. Although output declines less in the presence of expansionary monetary policy shock, it worsens the health condition of households by lowering the stock of health. On the contrary, more restriction of economic activity mitigates the spread of infection and flattens the declining curve of health stock. Hence, we get a trade-off between the severity of recession and the health status of the pandemic, similar to the results reported in Eichenbaum et al. (2020b).

Figure 5. Negative interest rate shock during COVID-19 pandemic
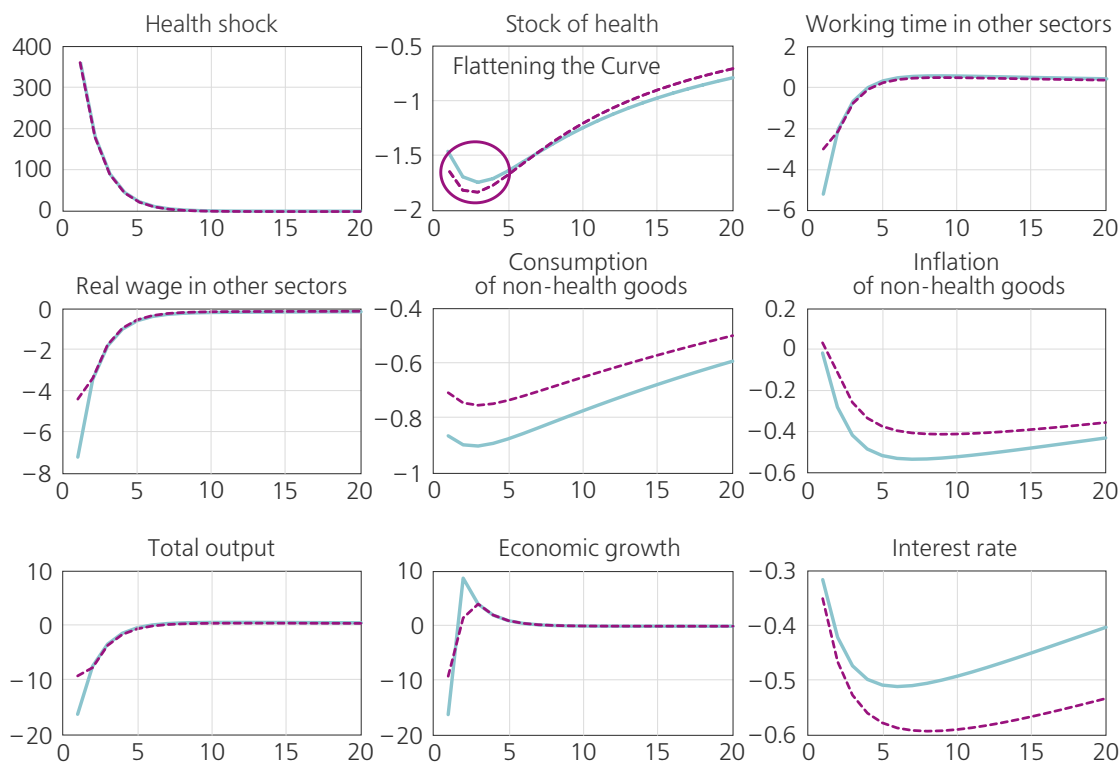

_ health shock

---- health and monetary policy shocks

\footnotetext{
4 This exercise is done using Dynare software (simultaneous health and monetary policy shocks).
} 


\subsection{Lockdown}

To model lockdown, we introduce wedge $\xi_{t}$ between the supply of and demand for non-health goods as follows:

$$
\left(1-\xi_{t}\right) Y_{N, t}=C_{N, t}+I_{N, t}+I_{H, t}+a\left(u_{N, t}\right) K_{N, t}+a\left(u_{H, t}\right) K_{H, t} .
$$

The results are presented in Figure 6. As a result of lockdown, economic activity declines, leading to a decrease in real wages. The decline in real wages means that the opportunity cost of isolation decreases, which motivates households to isolate more. This entails a modest decline of health stock. In contrast, total output declines more, which indicates the trade-off between output and health. In reality, targetted policies conducted by authorities may result in better performance in terms of both economic and health outcomes. This can be achieved by closing or restricting sectors with a high probability of getting infected and stimulating other sectors by aggregate expansionary or targetted policy. These kinds of policies are out of the scope of this paper.

\subsection{Optimal monetary policy}

This subsection applies an optimal monetary policy rule to minimise welfare losses created by health shock. The Ramsey planner in our economy minimises quadratic deviations of non-health inflation and health stock from their steady state, with the following objective function:

$$
E_{t} \sum_{j=0}^{\infty} \beta^{j}\left[\left(\pi_{N, t+j}-\pi_{N}^{s s}\right)^{2}+w\left(H_{t+j}-H^{s s}\right)^{2}\right] \rightarrow \min .
$$

In equation (4.5.1), $w$ is the relative weight of health in the planner's objective function. The Ramsey planner includes the interest rate as a policy instrument. For the optimal policy, we have two cases. The first takes only inflation into account and ignores health $(w=0)$, while the second cares more about health $(w=2)$. Figure 7 compares the two simulations under optimal monetary policy with the baseline where the interest rate follows the Taylor rule. When the policymaker cares only about inflation, he or she is able to smooth its variation by committing to keeping the interest rate close to zero (blue dashed line). This results in a decrease in health status compared to the baseline case. By introducing health variation to the planner's objective function, more care should be taken about health dynamics and interest rate increases, to prevent the further decline of health status (lilac dash-dotted line). The latter results in a greater decline of output compared to the case without health in the objective function. The results of simulation show that the central bank is able to conduct a beneficial policy both in terms of health and output, at the cost of inflation. But, in reality, it is impossible to run a fully committed policy, especially in developing countries. 
Figure 6. Lockdown during COVID-19 pandemic
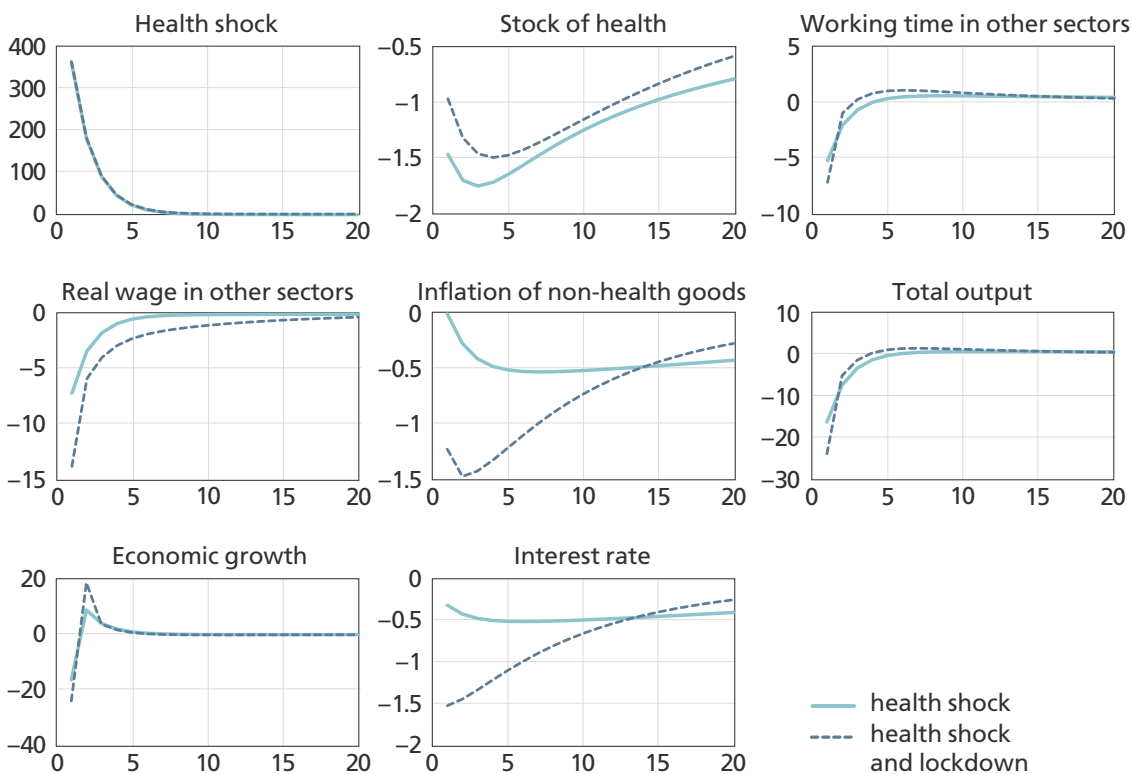

- health shock and lockdown

Figure 7. Optimal monetary policy during COVID-19 pandemic
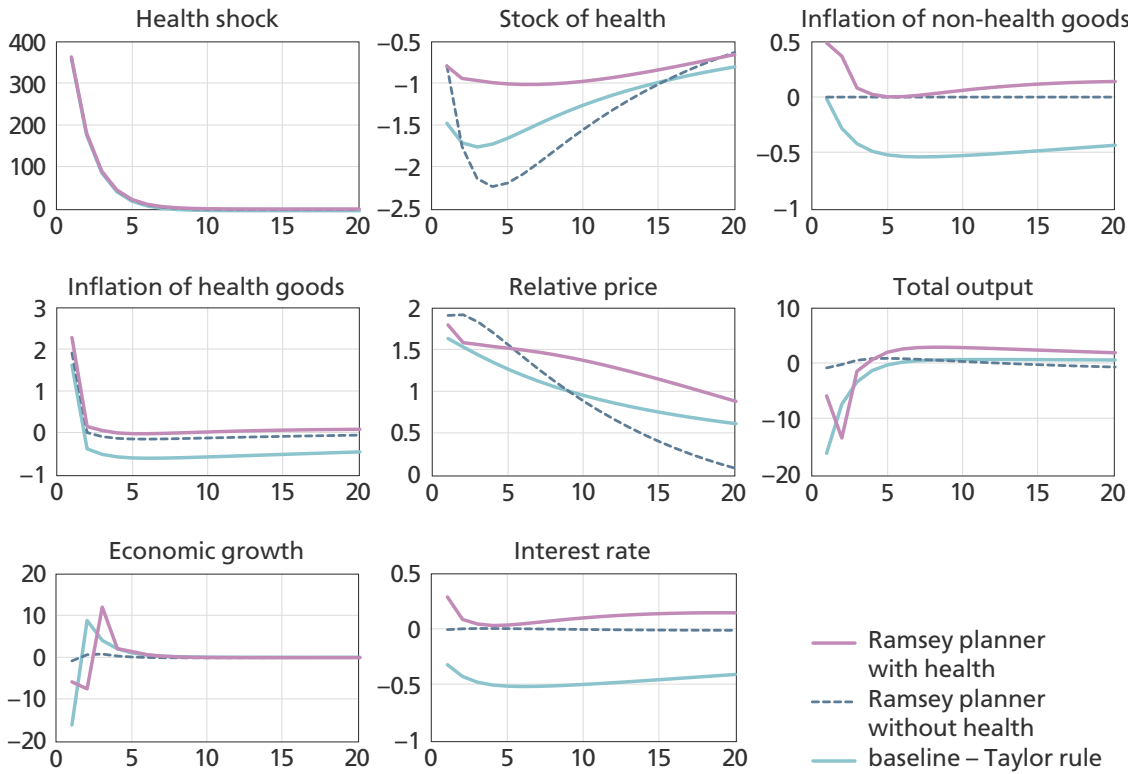

_ Ramsey planner with health

---- Ramsey planner without health

_ baseline - Taylor rule 


\subsection{Fiscal policy}

This subsection extends the model by introducing government policy into the model in a simple manner to test the effectiveness of fiscal policy in response to pandemic shock. We do not derive the government problem from micro-foundations and assume that government uses external borrowing to subsidise the economy.

As the model assumes a health externality on production, government subsidises firms to neutralise the negative effects health status has on production. Here, government acts with a subsidy in the production function given by the following:

$$
Y_{i, t}=A_{i, t}\left(K_{i, t}^{e f f}\right)^{\alpha_{i}}\left(N_{i, t} H_{t} \tau_{t}\right)^{1-\alpha_{N}} \quad i=H, N .
$$

The solution of the firm's problems gives marginal cost functions, where we have the same subsidy both for non-health and health firms:

$$
\begin{gathered}
M C_{H, t}=\left(\frac{r_{H, t}^{k}}{\alpha_{H}}\right)^{\alpha_{H}}\left(\frac{w_{H, t}^{r}}{1-\alpha_{H}}\right)^{1-\alpha_{H}} \frac{1}{A_{H, t}\left(H_{t} \tau_{t}\right)^{1-\alpha_{H}}} \frac{P_{N, t}}{P_{H, t}}, \\
M C_{N, t}=\left(\frac{r_{N, t}^{k}}{\alpha_{N}}\right)^{\alpha_{N}}\left(\frac{w_{N, t}^{r}}{1-\alpha_{N}}\right)^{1-\alpha_{N}} \frac{1}{A_{N, t}\left(H_{t} \tau_{t}\right)^{1-\alpha_{N}}} .
\end{gathered}
$$

Next, we define the simple fiscal rule which authorities use to neutralise the negative externality health has on production, represented by the following:

$$
\tau_{t}=\frac{1}{H_{t}} .
$$

Figure 8 shows the results of the simulation. The simple fiscal rule results in a smaller decline in production (blue dashed line) compared to the baseline case without fiscal policy (solid blue line). In contrast to this, direct fiscal support of production results in a deep decline in health status, because higher wages in the economy make isolation costly for households. Then, the planner keeps the production subsidy and chooses its path to minimise variations in economic growth and health, represented by the following objective:

$$
E_{t} \sum_{j=0}^{\infty} \beta^{j}\left[0.5\left(\frac{y_{t+j}}{y_{t+j-1}}-1\right)^{2}+\left(H_{t+j}-H^{s s}\right)^{2}\right] \rightarrow \min .
$$

The Ramsey optimiser gives a weight of 0.5 to economic growth and unit weight to health status. The lilac dash-dotted line in Figure 8 represents the results. A committed planner is able to benefit in terms of health status and economic growth by providing a huge amount of subsidy to production, which results in a higher increase of budget deficit. This policy creates inflation, and the monetary authority increases the interest rate to bring it back to the target. In reality, government is constrained in extending its budget deficit, and that is why we 
Figure 8. Government subsidy to production during COVID-19 pandemic
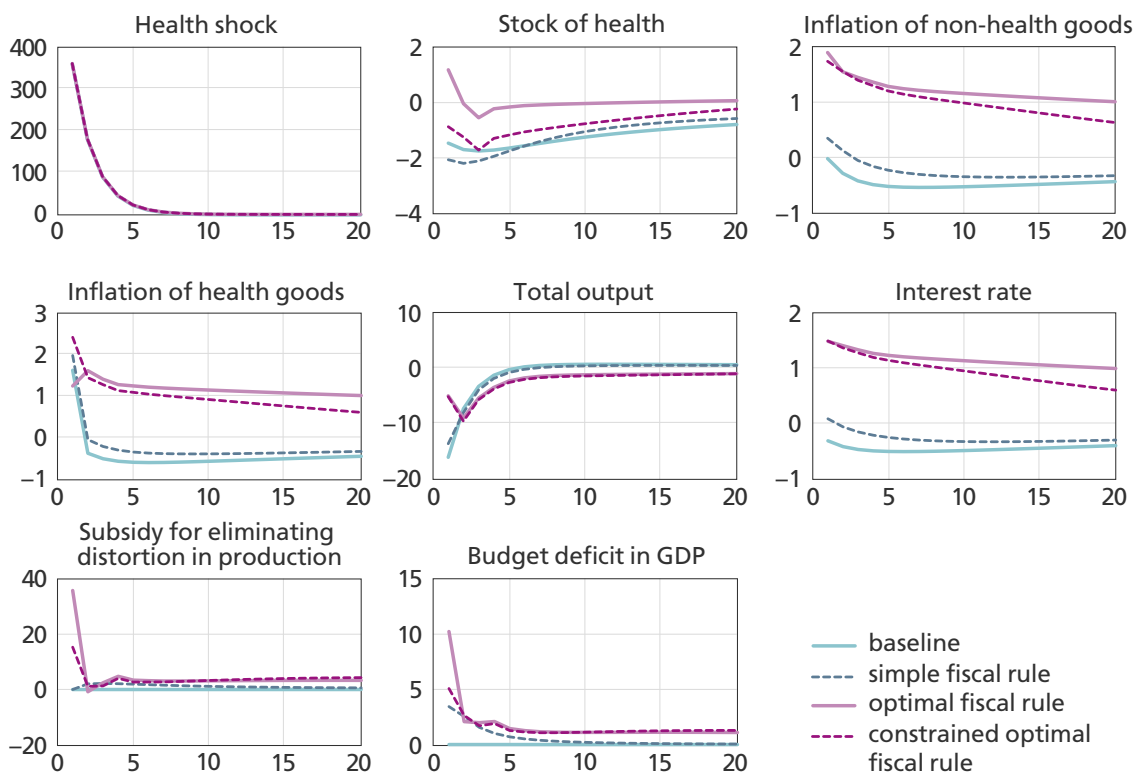

Figure 9. Public health spending during COVID-19 pandemic
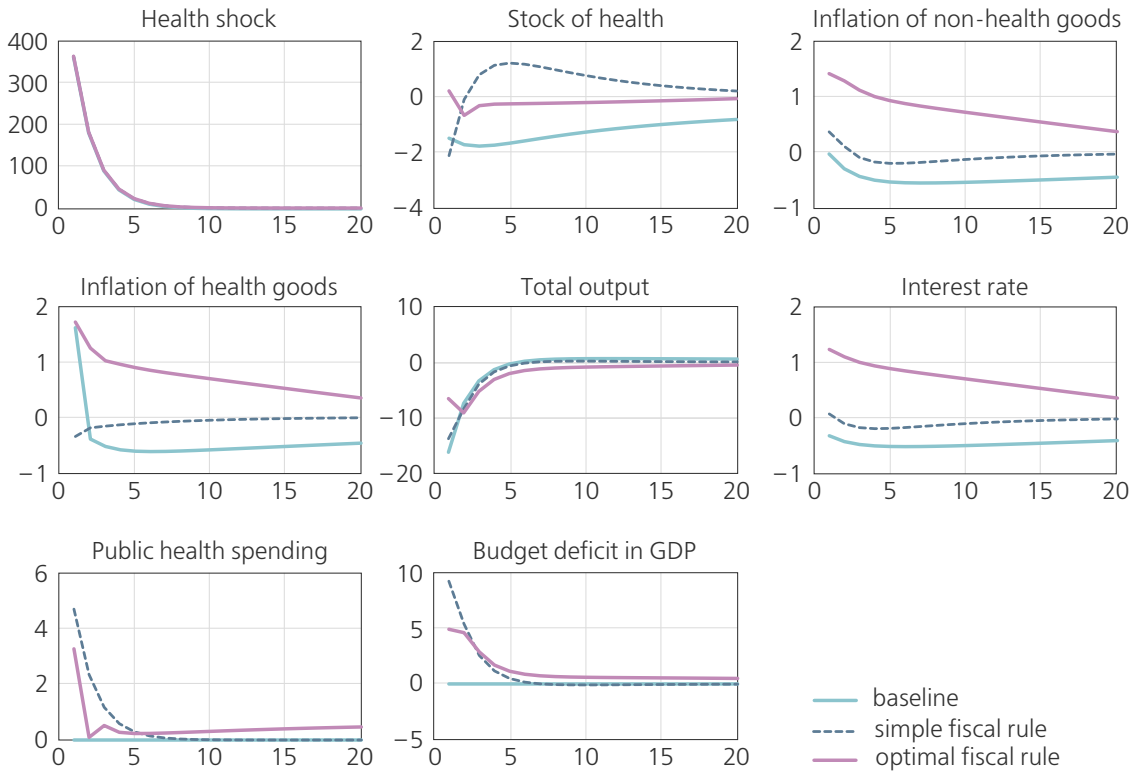

_ baseline

---- simple fiscal rule

_ optimal fiscal rule 
introduce a constraint on the budget deficit to 5\% of GDP, in order to have a more realistic simulation (lilac dotted line). Financially constrained government still prevents the large decline in health stock compared to the simple rule, but it performs worse than the unconstrained Ramsey planner.

In a lot of countries around the globe, governments finance the healthcare costs of people with COVID. The rest of this section introduces government financing of health into the model and estimates its impact on the economy and health status during the pandemic. The government acts in the model by a subsidy on health firms' marginal costs, which decreases the production costs of health firms, making them more competitive compared to the non-health sector. To recover the losses of the non-health sector as a result of becoming less competitive, government also finances non-health production. We have the same subsidy in the following two equations of the model:

$$
\begin{gathered}
M C_{H, t}=\left(\frac{r_{H, t}^{k}}{\alpha_{H}}\right)^{\alpha_{H}}\left(\frac{w_{H, t}^{r}}{1-\alpha_{H}}\right)^{1-\alpha_{H}} \frac{1}{A_{H, t} H_{t}^{1-\alpha_{H}}} \frac{P_{N, t}}{P_{H, t}}\left(\frac{1}{\tau_{t}}\right)^{\omega_{1}}, \\
Y_{N, t} \tau_{t}^{\omega_{2}}=C_{N, t}+I_{N, t}+I_{H, t}+a\left(u_{N, t}\right) K_{N, t}+a\left(u_{H, t}\right) K_{H, t},
\end{gathered}
$$

where $\omega_{1}$ and $\omega_{2}$ are sensitivity parameters. The fiscal authority follows a simple rule by subsidising the economy as long as the COVID shock exists:

$$
\tau_{t}=c \times \varepsilon_{t}^{\text {COVID-19 }} \quad(c=\text { constant })
$$

The paper also discusses the optimal rule, which maximises the objective function (4.6.5). The results are captured in Figure 9. Applying the simple fiscal rule (blue dashed line), government preserves the value of health stock for longer compared to the baseline. It finances the other sector as well, creating a huge budget deficit. On the other hand, a committed planner reduces the volatility of health stock significantly and supports economic activity, which creates inflationary pressures. A planner committed to minimising the volatility of economic growth and health stock is able to do so with a lower budget deficit compared with the simple fiscal rule but has a small positive deficit throughout the whole period of the simulation.

\section{Robustness}

This section checks the robustness of the results of different specifications of the model. The first exercise changes the separable utility function into a nonseparable with consumption and health status represented by the following equation: 


$$
E_{t} \sum_{j=0}^{\infty} \beta^{j}\left(\frac{\left(c_{N, t+j}^{\phi} H_{t+j}^{1-\phi}\right)^{1-\sigma}}{1-\sigma}-\chi_{N} \frac{N_{N, t+j}^{1+\varphi_{N}}}{1+\varphi_{N}}-\chi_{H} \frac{N_{H, t+j}^{1+\varphi_{H}}}{1+\varphi_{H}}\right) \rightarrow \max
$$

Hall and Jones (2007) say: 'However, even the direction of the effect is unclear: Is the marginal utility of consumption higher or lower for sick people? One can easily think of reasons why it might be lower. On the other hand, the marginal utility of having a personal assistant or of staying in a nice hotel with lots of amenities might actually be higher for people with a lower health status. Our separability assumption can be viewed as a natural intermediate case.'

Figure 13 in Appendix E plots the results of the robustness exercise with respect to the separability/non-separability of consumption and health in the utility function. Relaxing the assumption of separability, we obtain our main results.

The paper discusses investment in health as a Cobb-Douglas function of health consumption and isolation. Now we relax this assumption by introducing a CES function and avoiding the unit elasticity of substitution between these inputs:

$$
H_{t+1}=\left(1-\delta_{h}\right) H_{t}+\left[\alpha_{h} C_{H, t}^{1-v}+\left(1-\alpha_{h}\right)\left(\frac{W_{N, t}}{P_{H, t}} N_{M, t}\right)^{1-v}\right]^{\frac{1}{1-v}},
$$

where $v$ is the elasticity of substitution. We then test the robustness of the results with respect to critical values ( $v=90$ and $v=0.005$ ) of elasticity. As demonstrated in Figure 14 in Appendix E, the results are quite robust and do not differ significantly from the baseline.

In the last robustness exercise, we add the disutility from isolation time to the utility function, similarly to the disutility from labour, and remove it from budget constraint:

$$
E_{t} \sum_{j=0}^{\infty} \beta^{j}\left(\frac{C_{N, t+j}^{1-\sigma}}{1-\sigma}-\chi_{N} \frac{N_{N, t+j}^{1+\varphi_{N}}}{1+\varphi_{N}}-\chi_{H} \frac{N_{H, t+j}^{1+\varphi_{H}}}{1+\varphi_{H}}-\chi_{M} \frac{N_{M, t+j}^{1+\varphi_{M}}}{1+\varphi_{M}}+\psi \frac{H_{t+j}^{1-\eta}}{1-\eta}\right) \rightarrow \max .
$$

We construct this model with and without real wages in the health accumulation equation, and as can be seen in Figure 15 (Appendix E), the directions of the main variables are the same as those of the main specification.

\section{Conclusion}

This paper incorporates a health block into the standard New Keynesian closed economy DSGE model. To do this, we split production into health and non-health sectors and investigate the behaviour of households, firms, and the monetary authority in the model. Health status is modelled as a stock with a depreciation rate and investment. Households invest in their health by consuming medical goods and by isolating from society. We study the effect on the main 
macroeconomic variables from health shock, which embodies the outbreak of the COVID-19 pandemic in the economy.

We obtain that pandemic shock leads to a cut of the production and consumption of non-health goods. Shock results in a modest decline in inflation, and a policymaker acting under a Taylor rule decreases the interest rate.

The paper analyses the consequences of expansionary macroeconomic policy conducted by monetary authorities. Although the reduction of the interest rate mitigates the decline in total output, it deepens the decline of the health stock curve. Thus, in order to flatten the curve and improve society's health conditions, the authorities have to restrict economic activity by allowing a more severe recession. In other words, there exists a trade-off between economic activity and the health consequences caused by an pandemic. These results are in line with the results obtained by Eichenbaum et al. (2020b).

Then the paper discusses optimal monetary policy in times of pandemic. We find that a planner is able to prevent huge decline in health stock and output, but creates some inflation. Furthermore, simple government with subsidies is introduced in an ad hoc manner. First, it tries to correct distortions in production arising from the decrease of health status. A committed planner acts in a way to prevent the decline of health and results in a smaller decline of output. This generates a budget deficit of about $10 \%$ of GDP. But this policy creates some inflation and the central bank increases the interest rate. If government faces constraints on budget deficits, health declines more compared to the simulation with unconstrained government. Second, government expands the health sector by budget financing. This simulation shows that such type of policy is beneficial to the economy and health development, but leads to an increase in the budget deficit. The paper does some robustness analysis as well. Our main results are consistent across different specifications of the model.

There are some potential issues regarding further research worth noting.

First, it would be useful to extend the model by constructing a small open economy DSGE model and including a risk premium with health shock, which would introduce additional uncertainty.

Furthermore, one can add capital transformation from one production sector to another. This does not provide much benefit from a monetary policy perspective, though. The problem is partially solved by introducing effective capital into the model, which is presented as a function of capital stock and utilisation of capital.

It would be interesting to introduce a micro-founded government into the model, with its aggregate and sector-specific tools to perceive the optimal policy response to stabilise a health crisis.

Appendices are available at

http://rjmf.econs.online/en; dx.doi.org/10.31477/rjmf.202004.18 


\section{References}

Acemoglu, D., Chernozhukov, V., Werning, I. and Whinston, M. D. (2020). A Multi-Risk SIR Model with Optimally Targeted Lockdown. NBER Working Paper, N 27102. doi: $10.3386 /$ w27102

Adda, J. (2016). Economic Activity and the Spread of Viral Diseases: Evidence from High Frequency Data. Quarterly Journal of Economics, 131(2), pp. 891-941.

Barrios, J. M. and Hochberg, Y. (2020). Risk Perception Through the Lens of Politics in the Time of the COVID-19 Pandemic. NBER Working Paper, N 27008. doi: 10.3386/w27008

Bigio, S., Zhang, M. and Zilberman, E. (2020). Transfers vs Credit Policy: Macroeconomic Policy Trade-offs during COVID-19. NBER Working Paper, N 27118. doi: 10.3386/w27118

Calvo, G. A. (1983). Staggered Prices in a Utility-Maximizing Framework. Journal of Monetary Economics, 12(3), pp. 383-398. doi: 10.1016/0304-3932(83)90060-0

Christiano, L. J., Trabandt, M. and Walentin, K. (2011). Introducing Financial Frictions and Unemployment into a Small Open Economy Model. Journal of Economic Dynamics and Control, 35(12), pp. 1999-2041. doi: 10.1016/j.jedc.2011.09.005

Durante, R., Guiso, L. and Gulino, G. (2020). Asocial Capital: Civic Culture and Social Distancing during COVID-19. Barcelona Graduate School of Economics Working Papers, N 1181.

Eichenbaum, M. S., Rebelo, S. and Trabandt, M. (2020a). Epidemics in the Neoclassical and New Keynesian Models. NBER Working Paper, N 27430. doi: 10.3386/w27430

Eichenbaum, M. S., Rebelo, S. and Trabandt, M. (2020b). The Macroeconomics of Epidemics. NBER Working Paper, N 26882. doi: 10.3386/w26882

Fernández-Villaverde, J. (2010). The Econometrics of DSGE Models. SERIEs - Journal of the Spanish Economic Association, 1, pp. 3-49. doi: 10.1007/s13209-009-0014-7

Fornaro, L. and Wolf, M. (2020). COVID-19 Coronavirus and Macroeconomic Policy. Barcelona Graduate School of Economics Working Papers, N 1168.

Galí, J. and Monacelli, T. (2005). Monetary Policy and Exchange Rate Volatility in a Small Open Economy. Review of Economic Studies, 72(3), pp. 707-734. doi: 10.1111/j.1467-937X.2005.00349.x

Guerrieri, V., Lorenzoni, G., Straub, L. and Werning, I. (2020). Macroeconomic Implications of COVID-19: Can Negative Supply Shocks Cause Demand Shortages? NBER Working Paper, N 26918. doi: 10.3386/w26918

Hall, R. E. and Jones, C. I. (2007). The Value of Life and the Rise in Health Spending. Quarterly Journal of Economics, 122(1), pp. 39-72. doi: 10.1162/qjec.122.1.39

Krueger, D., Uhlig, H. and Xie, T. (2020). Macroeconomic Dynamics and Reallocation in an Epidemic: Evaluating the 'Swedish Solution'. NBER Working Paper, N 27047. doi: $10.3386 /$ w27047

Maloney, W. and Taskin, T. (2020). Determinants of Social Distancing and Economic Activity during COVID-19: A Global View. World Bank Policy Research Working Paper, N 9242. 
Sims, E. R. and Wu, J. C. (2019). The Four Equation New Keynesian Model. NBER Working Papers, N 26067. doi: 10.3386/w26067

Smets, F. and Wouters, R. (2007). Shocks and Frictions in US Business Cycles: A Bayesian DSGE Approach. American Economic Review, 97(3), pp. 586-606. doi: 10.1257/aer.97.3.586

Torój, A. (2013). Why Don't Blanchard-Kahn Ever 'Catch' Flu? And How it Matters for Measuring Indirect Cost of Epidemics in DSGE Framework. Central European Journal of Economic Modelling and Econometrics, 5(3), pp. 185-206.

Yagihashi, T. and Du, J. (2015). Health Care Inflation and Its Implications for Monetary Policy. Economic Inquiry, 53(3), pp. 1556-1579. doi: 10.1111/ecin.12204 